\title{
Periodontal Health Status of A Group of (Non- Institutionalized) Mentally Disabled Children in Khartoum State
}

\author{
NT Hashim1, B Gobara², I Ghandour
}

\begin{abstract}
Aim: The aim of this study is to assess the periodontal health status and its determinants among aroup of mentally disabled children in Khartoum State and to compare it with a control group of children of normal intelligence.

Methods: Thirty seven mentally disabled children aged 8-10 years were examined at five centres of mentally disabled children in Khartoum State. A control group with normal intelligence quotient of a similar age and socioeconomic status was selected from schools nearby the centres visited. Both mentally disabled children and the children in the control group were examined for their plaque index, gingival index and periodontal pocket depth. A comparison was made between the mentally disabled children and the healthy children as well as between the subgroups of the mentally disabled children (mild, moderate, and severe). Questionnaires concerning the degree of mental disability, level of parent education, role of parents toward child oral health, were also used.

Results: The results revealed that the mentally disabled children showed higher scores of plaque and gingival index (1.9, 1.7 respectively) when compared with the plaque and gingival index of the control group (0.6, 0.6 respectively). No increase in gingival sulcus depth in both study and control group was found. According to the degree of mental disability there was statistically significant difference in plaque and gingival index among the mild, moderate and severe subgroups $(\mathrm{P}=0.001)$, the plaque and gingival index tend to increase with the severity of mental retardation. Conclusion. Mentally disabled children showed more plaque when compared with healthy controls. Periodontal disease was more prevalent among mentally disabled children as presented in the form of gingivitis and the degree of severity depends on the degree of mental disability.
\end{abstract}

Keywords: Mental disability, Periodontal health

${ }^{1}$ BDS, MSC,LDDS

Periodontist, Bahri Dental Teaching Hospital,

Khartoum, Sudan

${ }^{2}$ Assistant Professor

Dept. of Periodontology, Faculty of Dentistry,

University of Khartoum, Khartoum, Sudan

${ }^{3} \mathrm{BDS}, \mathrm{MSc}, \mathrm{DDPH}$

Professor of Periodontology,

Faculty of Dentistry, University of Khartoum,

Khartoum, Sudan

\section{Contact Autbor}

Dr. Nada Tawfig Hashim nadatawfig@yahoo.com

J Oral Health Comm Dent 2012;6(1)10-13

\section{INTRODUCTION}

Tr $\mathrm{t}$ is estimated that there are $500 \mathrm{mil}$ lion people with disabilities world wide, the largest number of whom is to be found in Majority World (1). The American Association on intellectual and developmental disabilities (AAIDD) defines mental disability as significant limitations both in intellectual functioning and in adaptive behaviour as expressed in conceptual, social, and practical adaptive skills. This disability is manifested during the developmental period (before age 18)(2). Intellectual limitations refer to an Intelligence Quotient (IQ) which falls two standard deviations below the population mean of $100(<70)$ and adaptive functioning limi- tations refer to impairments in at least two out of ten skill areas(3). Mental retardation has been classified by diagnostic and statistical manual of mental disorders $4^{\text {th }}$ edition (DSM-4) as mild (IQ. 50-70), moderate (IQ. 34-55), severe (IQ. 20-40), or profound (I.Q. less than 20) mental retardation subgroups (4)According to the fourth census of Sudan (1993), all the disabled constitute about 15.9 per 1000 in the northern state of Sudan and the mentally retarded about 1.5 per 1000 , while in Khartoum state all the disabled constitute 11.6 per 1000 and the mentally retarded 1.1 per 1000. The figures of the mentally retarded children in Sudan is underestimated for many reasons ; people in Sudan do not 
give the true number of the family members especially the presence of mentally disabled children and tend to deny their existence because of the impact, mainly on females as it reduces their chances of marriage (5).

Poor oral hygiene and periodontal diseases represent major problems for the mentally disabled children (Tenisi, 1981) (6) (Martens et al., 2000) (7). The poorer oral health of people with disabilities is attributable to number of causes. In part, lack of daily oral hygiene care procedures (8).

Gabre and Gahnberg (1994) found that the oral health status of individual with mental disability is associated with the severity of the condition (9). The etiology of the disability, IQ level, parent's level of education, and poor economic status were also found to be influencing the oral health status of the mentally disabled children $(10,11)$.

Although oral health care is becoming an increasingly an integrated part of an overall medical care, it is one of the greatest unattended health needs of the disabled people (12). In developing countries the situation is even worse with lack of both medical and oral health care facilities and absence of dental supervision in institutions and day centers for children with special needs. Therefore, the present study was carried out to determine the periodontal health status among a group of mentally disabled children attending public day centers for children with special needs in Khartoum State-Sudan.

\section{MATERIAL AND METHODS}

Prior to the conduct of the study, ethical approval was obtained from Ethical committee for research of the dental faculty board of Khartoum University -and from the ethical committee of the ministry of social affairs-Khartoum.

\section{SAMPLE}

The study sample consisted of children attending five different public day centers for individuals with special needs in Khartoum state-Sudan. The names and loca- tions of the centers were taken from the Ministry of welfare and Social Affairs. The children attended the center at 8 am and left at $3 \mathrm{pm}$. Only children with mental disabilities (age 8-10) were included in the study group. Children with motor disabilities, serious medical problems or those who take regular medications were excluded. The total number of children in this age group was 58. Written consents were sent to all parents of the children scheduled for examinations. Only 37 children were included in the final examinations because of some logistic difficulties including transportation, refusal of the examination by the child or the parents. A control group of age -matched children with normal intelligent was recruited from schools nearby the centers visited.

\section{DATA COLLECTION}

A structured questionnaire was sent to be completed by the parents. The questionnaire included information about the child's demographic data including child's age, gender and level of parent's education. Information about oral hygiene habits including the frequency of tooth brushing and the role of the parents towards the child's oral health were also obtained. The degree of mental disability was registered from the child's records in the institute. Children were divided accordingly into those with mild mental disability (IQ. 6752), moderate mental disability (IQ. 51-36), and severe mental disability (IQ. d" 35). Of the whole sample, only three (1.1\%) were Down's syndrome patients and were categorized in the moderate mentally disabled group.

\section{ORAL EXAMINATIONS}

Dental examinations were performed using proper light, dental mirror and periodontal probe (William pattern). Periodontal assessments included all teeth present in the mouth. The following parameters were recorded: Plaque Index (PI), gingival Index (GI), and Periodontal Pocket Depth (PPD). Plaque and gingival index were recorded according to the criteria given by Loeand Silness $(13,14)$. For periodontal pocket depth (PPD) 4 sites were probed (mesial and distal) on the buccal and palatal (lingual) surfaces of each tooth. The examinations were carried by one examiner (T.N) with the help of a dental assistant.

\section{STATISTICAL DATA ANALYSIS}

All data were analysed using SPSS. The mean plaque index, mean gingival index and mean pocket depth were recorded. Comparisons of the parameters means between study and control group were made using student t-test.

\section{RESULTS}

\section{The Study Group}

The study group consisted of 37 mentally disabled children (mean age 10.6土 1.6). 56.8 $\%$ were males $(n=21)$ and $43.2 \%$ were females $(n=16)$. Males had significantly higher mean plaque index $(\mathrm{P}<0.001)$ and mean gingival index $(\mathrm{P}=0.001)$ than $\mathrm{fe}-$ males (Table 1).

No pocket depth greater than $3 \mathrm{~mm}$ was recorded.

\section{Periodontal Parameters Related to} the Degree of Mental Retardation $32.4 \%$ of the study group were mildly disabled ( $\mathrm{n}=12), 45.9 \%$ were moderately disabled $(n=17)$, and $21.6 \%$ represented severely disabled children $(n=8)$. The mean plaque index of the moderately disabled children was significantly higher than that of the mildly disabled children $(\mathrm{P}<0.01)$. The severely disabled children showed the highest plaque index with statistically significant difference when compared with the

Table 1: Mean plaque index and gingival index among males and females in the study group

\begin{tabular}{|lccc|}
\hline & No. (\%) & $\begin{array}{c}\text { Mean plaque } \\
\text { index }( \pm S D)\end{array}$ & $\begin{array}{c}\text { Mean gingival } \\
\text { index }( \pm S D)\end{array}$ \\
\hline Males & $21(56.8)$ & $2.6 \pm 0.2$ & $2.3 \pm 0.1$ \\
Females & $16(43.2)$ & $1.9 \pm 0.1$ & $1.6 \pm 0.2$ \\
\hline \multicolumn{3}{r}{$t=12.9$} & $P=0.001$ \\
\hline
\end{tabular}


PERIODONTAL HEALTH STATUS OF A GROUP OF (NON- INSTITUTIONALIZED) MENTALLY DISABLED CHILDREN IN KHARTOUM STATE

moderately disabled children $(\mathrm{P}=0.001)$.

The mean gingival index of the moderately disabled children was significantly higher than that of the mildly disabled children $(\mathrm{P}=0.001)$. The severely disabled children had the highest gingival index with statistically significant difference when compared with the moderately disabled children $(\mathrm{P}=0.001)$. The periodontal health parameters within these subgroups are shown in Table (2).

Table 2: Periodontal parameters (plaque index and gingival index) of the study group related to the degree of mental disability

\begin{tabular}{|llcc|}
\hline & Degree of mental disability & Mean & SD \\
\hline Plaque index & Mild & 1.6 & 0.3 \\
& Moderate & 1.9 & 0.2 \\
& Severe & 2.2 & 0.2 \\
\hline Gingival index & Mild & 1.5 & 0.2 \\
& Moderate & 1.7 & 0.04 \\
& Severe & 1.8 & 0.03 \\
\hline \multicolumn{2}{c}{$t=3.75$} & $P=0.001$ & \\
\hline
\end{tabular}

Table 3: Periodontal parameters (plaque index and gingival index) of the study group related to the tooth brushing helper

\begin{tabular}{|lllcl|}
\hline & Tooth brushing habits & No. (\%) & Mean & SD \\
\hline \multirow{2}{*}{ Plaque index } & Brushing with help & $15(40.5)$ & 1.8 & 0.1 \\
& Brushing without help & $22(59.5)$ & 2.0 & 0.3 \\
\hline \multirow{2}{*}{ Gingival index } & Brushing with help & $15(40.5)$ & 1.6 & 0.1 \\
& Brushing without help & $22(59.5)$ & 1.8 & 0.1 \\
\hline \multicolumn{4}{c}{$t=2.86$} & \multicolumn{3}{c}{$P=0.01$} \\
\hline
\end{tabular}

Table 4: The plaque index among study group related to the frequency of tooth brushing

\begin{tabular}{|lccc|}
\hline Tooth brushing frequency & No.(\%) & Mean Plaque Index & SD \\
\hline Brushing once & $32(86.5)$ & 1.9 & 0.2 \\
Brushing twice & $5(13.5)$ & 2.0 & 0.3 \\
\hline \multicolumn{5}{r}{$t=1$} & $P=0.5$ & \\
& & & \\
\hline
\end{tabular}

Table 5: The mean plaque index and gingival index among the study and the control group

\begin{tabular}{|llccc|}
\hline & & No. & Mean & SD \\
\hline Plaque index & Study & 37 & 1.9 & 0.2 \\
& Control & 37 & 0.6 & 0.3 \\
\hline Gingival index & Study & 37 & 1.7 & 0.1 \\
& Control & 37 & 0.6 & 0.2 \\
\hline \multicolumn{2}{|c}{$t=21.7$} & & $P=0.001$ & \\
\hline
\end{tabular}

Table 6: The mean plaque index related to frequency of tooth brushing

\begin{tabular}{|llccc|}
\hline & & No. (\%) & Mean & SD \\
\hline Brushing once & Study & $32(86.5)$ & 1.9 & 0.2 \\
& Control & $18(48.6)$ & 0.7 & 0.4 \\
\hline \multirow{2}{*}{ Brushing twice } & Study & $8(21.6)$ & 2.04 & 0.3 \\
& Control & $19(51.4)$ & 0.5 & 0.2 \\
\hline \multirow{2}{*}{$t=13.3$} & & $P=0.001$ & \\
\hline
\end{tabular}

The Periodontal Parameters (Plaque Index and Gingival Index) Related to the Tooth Brushing Habits

Mentally disabled Children who brush their teeth without help had significantly higher plaque scores than those who were helped by others $(\mathrm{P}<0.01)$. The mean gingival index was higher among mentally disabled children who brush their teeth without help than those who were helped by others. The difference was statistically significant $(\mathrm{P}=0.01)$ (Table 3).

Plaque scores were higher among those who brushed twice daily than those who brushed once per day, however the difference was not statistically significant $(\mathrm{P}=0.5)$ (Table 4).

The study group vs. the control group

The control group consisted of 37 children (mean age $10 \pm 1.5$ ). Males and females (51\%, 49\% respectively).

The mean plaque index and gingival index were significantly higher in the study group than in the control group $(\mathrm{P}<0.001)(\mathrm{Ta}-$ ble 5).

Mentally disabled children who brush their teeth once a day had significantly higher plaque scores than those in the control group $(\mathrm{P}=0.001)$. This was also observed among mentally disabled children who brush their teeth twice a day who showed higher plaque scores than children in the control group $(\mathrm{P}=0.001)$ (table 6) (figure 1)

\section{DISCUSSION}

Most studies assessing oral health status among people with intellectual disabilities reported poor levels of oral hygiene $(11,15,16,17)$ which is in accordance with the findings of this study. The mentally disabled subjects of the present study had higher plaque and gingival index than that found in non-disabled children of comparable age groups. We have chosen this age group to avoid hormonal disturbances related to puberty. Our results confirm the findings of other studies concerning the higher plaque and gingival index among 
individuals with mental disabilities $(7,15,18)$.

Significant difference was found in the mean plaque and gingival index among males and females in the mentally disabled group in the present study which can indicate that the family has more attention towards the oral hygiene of the mentally disabled females than the males of the same group. These results are similar to the findings reported by Connick (2001) (19), although inconsistent with those findings by Kao et al (1991) (20) who concluded that the gender has no influence on plaque and gingival index among mentally disabled children.

According to the degree of mental retardation, there were statistically significant differences in plaque and gingival index between the mild, moderate and severe mentally disabled children. The plaque and gingival index tend to increase with the severity of the mental disability. Similar results have been shown earlier by Martens et al., ( 2000) (7), Rao et al., (2005) (17), and Kawagushi and Nakashima, (1990) (21). In this study there was statistically significant difference in plaque and gingival index among mentally disabled children who brush their teeth by themselves and those who were helped by others with higher plaque scores in children who used to brush their teeth by themselves than those who were helped other persons, and this is similar to the findings reported in earlier studies $(22,23)$ but disagree with the findings by Nielsen, (1990) (24) who found higher plaque and gingival index among disabled children when the child and the parents together were responsible for the child's tooth brushing than when the children brushed their teeth on their own. Regarding the frequency of teeth cleaning the study showed higher plaque index in mentally disabled children who had brushed their teeth twice than those who had brushed their teeth once a day, and the difference was not statistically significant. The depth of the gingival sulcus for both mentally disabled and non-disabled children was measured. No periodontal pockets of depth $>3 \mathrm{~mm}$ were found, hence the result were not worthy to be computed and presented, and this was even true for the mentally retarded children with Down's syndrome, most probably due to the very small percentage of down's syndrome patients in our sample. However, this may differ from the findings of other investigators who showed that early signs of periodontitis are frequently seen in Down's syndrome children as early as 11 years of age (25). but agrees with the finding of De fiueiredo et al., (2005) (26).

\section{CONCLUSION}

Taking into consideration the results of the present study, mentally disabled children tend to show poorer oral hygiene level and consequently more gingival inflammation when compared to the non-disabled children of the same age group. In addition the oral health status of the present population was influenced by degree of mental disability. Oral hygiene improvement of the non-institutionalized mentally disabled children can be achieved by teaching and motivating parents and children. Furthermore, Oral health promotion programs should be aimed specifically at parents of disabled children and special needs schools.

\section{REFERENCES}

1. Watson N. Barriers, discrimination and prejudice. In: Disability and oral care, Nunn J ed FDI World Dental Press Ltd, London, 2000;15-20.

2. Schalock RL, Luckasson RA, Shogren KA, et al. The renaming of mental retardation: Understanding the change to the term intellectual disability. Intellectual and Developmental Disabilities 2007;45(2):116-24.

3. American Association on Mental Retardation (AAMR) April 20, 2000.

4. American Psychiatric association (APA) .Diagnostic and statistical manual of mental disorders, fourth edition (DSM-IV), Washington DC 1994.

5. Fourth population census of Sudan 1993, final tabulation, Sudan Northern State vol.2, Economic and Social characteristics, department of statistics, Census office Khartoum June 1995;11:151-59.

6. Tesini DA. An annotated review of the literature of dental caries and periodontal disease in mentally and physically retarded individuals. Spec Care Dent 1981;1:75-87.

7. Martens L, Marks L, Goffin G, et al. Oral hygiene in 12-year old disabled children in Flanders, Belgium, related to manual dexterity. Comm Dent Oral Epidemiol 2000;28:73-80.

8. Waldman, et al. Dental care of children with mental retardation: thoughts about the Americans with Disabilities Act. J Dental child 1999;65:487-91.

9. Gabre P, Gahnberg L. Dental health status of mentally retarded adults with various living arrangements. Spec Care Dentist 1994; 14:20307.

10. Jain M, Mathur A, Sawla L, Choudhary G, Kabra $\mathrm{K}$, Duraiswamy $\mathrm{P}$, et al. Oral health status of mentally disabled subjects in India. J Oral Sci 2009;51(3):333-40.

11. Kumar S, Sharma J, Duraiswamy P, Kulkarni $S$. Determinants for oral hygiene and periodontal status among mentally disabled children and adolescents. J Indian Soc Pedod Prev Dent 2009;27:151-57.

12. Hennequin M, Faulks D, Roux O. Accuracy of estimation of dental treatment need in special care patients. J Dent 2000;28:131-36.

13. Loe H, Silness J. Periodontal disease in pregnancy. I. Prevalence and severity. Acta Odontol Scand 1963;21:533-51.

14. Silness J, Loe H. Periodontal disease in pregnancy. II. Correlation between oral hygiene and periodontal condition. Acta Odontol Scand 1964;22:121-35.

15. Nunn. The dental health of mentally and physically handicapped children: a review of the literature. Community Dent Health. 1987;4(2):157-68.

16. Gizani S, Declerck D, Vinckier F, Martens L, Marks L, Goffin G. Oral health condition of 12year-old handicapped children in Flanders (Belgium). Community Dent Oral Epidemiol 1997;25(5):352-57.

17. Rao Dinesh, Hegde Amitha, Avatar Kishan Munshi. Oral hygiene status of disabled children and adolescents attending special schools of south canara, India. Hong Kong Dental Journal 2005;2:107-13.

18. Seymen F, Aytepe Z, Kiziltan B. Oral health status in children with Down syndrome. J Disabil Oral Health 2002; 3:62-67.

19. Connick CM, Fos PJ, Barsley RE. Gender differences in special needs population. Dent Clin North Am 2001;45(3):541-53.

20. Kao CT, Chou MY. Survey on oral hygiene status in children with Down's syndrome and mental retardation. Zhonghua ya yi xue hui za zhi 1991;10(1):13-19.

21. Kawagushi T, Nakashima M. Oral finding of institutionalized handicapped children. Fukvoka Shika Daigaku Gakkai Zasshi, 1990;17(1):1321.

22. Svatum B, GjermnoP. Oral hygiene, periodontal heath and needs among institutionalized mentally subnormal persons in Norway. Acta Odontol Scand 1978;36(2):89-95.

23. Viglid M. Periodontal condition in mentally retarded children. Community Dental Oral Epidemiology 1985;13(1):24-27.

24. Nielsen LA. Plaque and gingivitis in children with cerebral palsy, mental and motor handicapped, Tandlaegernes tidssker 1990;5(11):316-20.

25. Modeer T, Barr M, Dahllof G. Periodontal disease in children with Down's syndrome. Scand J Dental Res 1990;98:228-34.

26. De fiueiredo LC, Feres M, Salvador SL. Halitosis and periodontal disease in subjects with mental disability. Oral Diseases 2005; 11(1):83. 